\title{
EVIDENZA DI UN GENOTIPO 4 DI HCV IN TOSSICODIPENDENTE PRECEDENTEMENTE HCV POSITIVA (GENOTIPO Ia/lb) ED SVR DOPO TERAPIA CON PEG-IFN + RIBAVIRINA
}

Focà A.', Quirino A.', Barreca G.S.', Lamberti A.G.', Capicotto R.', Di Cello C.', Caroleo B. ${ }^{2}$, Tallarico M. ${ }^{2}$, Guadagnino V. ${ }^{2}$

Cattedra di Microbiologia' e Cattedra di Malattie Infettive², Facoltà di Medicina e Chirurgia,

Università degli Studi "Magna Graecia” di Catanzaro.

Introduzione. Sono stati riportati casi di infezione con genotipo diverso da quello dell'infezione primaria, in talassemici periodicamente emotrasfusi (Lai, 1994; Meng, 1994) ed in tossicodipendenti (Proust, 2000 Payen, 1998). In questo studio è stato messo in evidenza un genotipo 4 di HCV in una paziente tossicodipendente (TD) precedentemente positiva per HCV $1 \mathrm{a} / 1 \mathrm{~b}$.

Metodi. L'RNA virale veniva estratto da campioni di siero, rivelato mediante RT-PCR (Cobas Amplicor HCV, Roche Diagnostics) quantizzato mediante PCR quantitativa (Cobas Amplicor HCV monitor 2.0, Roche Diagnostics) e genotipizzato mediante ibridazione inversa su supporto solido (Versant HCV genotipo LIPA, Bayer).

Il campione di siero proveniva da una donna di 27 anni, TD eroinomane e cocainomane da 10 anni seguita dal 2000 presso l'U.O. di Malattie Infettive e monitorata per HCV-RNA presso l'U.O. di Microbiologia e Virologia Clinica del P.U. "Mater Domini" di Catanzaro perché affetta da Epatite Cronica C, genotipo 1a/1b. Nel 2002, dopo epatobiopsia conclusiva per EC con attività necroinfiammatoria severa e fibrosi porto-periportale moderata (G18S3 secondo Ishack), iniziava trattamento con PEG-Interferone alfa-2b alla dose di $1,5 \mu \mathrm{g} / \mathrm{Kg} /$ settimana s.c., associato a Ribavirina 10,6 $\mathrm{mg} / \mathrm{Kg} /$ die per os; si otteneva normalizzazione delle ALT e negativizzazione dell'RNA dopo 4 settimane di terapia, condizione che persisteva fino alla $48^{\circ}$ settimana di trattamento e dopo ben 12 mesi dalla sospensione.

Risultati. Nel mese di maggio del 2005 si rilevava modesta ipertransaminasemia e positività per HCV-RNA $(1780 \mathrm{U} / \mathrm{ml})$ genotipo 4. La paziente riferiva che quattro mesi prima era ricaduta nelle droghe d'abuso per via inalatoria (cocaina), ammettendo scambio di "cannuccia" ma non rapporti sessuali a rischio.

Conclusioni. L'evidenza di un genotipo diverso da noi riscontrato troverebbe come spiegazione più plausibile che si tratti di una reinfezione instauratasi durante la sospensione della terapia.

Dal punto di vista microbiologico e molecolare possiamo escludere una eventuale mutazione del genotipo precedentemente rilevato o una selezione farmaco-indotta? 